\title{
Efeitos de diferentes estratégias de controle no ambiente de armazenamento de grãos em regiões tropicais e subtropicais
}

\author{
Daniela de Carvalho Lopes ${ }^{1}$, José Helvecio Martins², Paulo Marcos de Barros Monteiro³, \\ Adílio Flauzino Lacerda Filho ${ }^{4}$
}

\section{RESUMO}

Neste trabalho, estratégias de controle para aeração de grãos baseadas em temporizador, termostato e termostato combinado com umidostatos foram comparadas ao controlador AERO. Apesar de simples, as três primeiras estratégias são amplamente empregadas, resultando em controles confiáveis e em grande aceitação por parte dos produtores. O AERO foi desenvolvido na Universidade Federal de Viçosa com o objetivo de difundir e facilitar a utilização de estratégias mais sofisticadas pelos produtores. Este controlador atua com base em dados medidos em tempo real e na simulação do processo de aeração. Os resultados mostraram que os tempos requeridos para aeração, além dos níveis de deterioração, das temperaturas e dos teores finais de água dos grãos foram parecidos para as quatro estratégias analisadas quando se considerou as melhores configurações para as três estratégias simples. Entretanto, o AERO apresentou um controle mais eficiente, resfriando a massa de grãos mais rapidamente e minimizando as oscilações de temperatura e de teor de água dos grãos durante o processo de aeração. Outra vantagem do AERO é sua capacidade de ajustar automaticamente as suas condições de controle de acordo com as condições climáticas da região onde o sistema está implantado.

Palavras-chave: Grãos armazenados, estratégia de controle, aeração, simulação

\section{ABSTRACT}

\section{Effects of different control strategies on grain storage in tropical and subtropical regions}

In this work, control strategies for grain aeration based on timer, thermostat and thermostat combined with humidistats were compared to the AERO controller. In spite of the simplicity of the first three strategies, they are widely used, resulting in reliable control and high acceptance by farmers. AERO was developed at the Federal University of Viçosa to spread and facilitate the use of more sophisticated strategies by farmers. This controller is based on real time data acquisition and process simulation. The results showed that aeration time, as well as final grain deterioration rates, temperatures and moisture contents were similar among the four strategies, when considering the best set-points of the three simple controllers. However, AERO resulted in a more effective control, cooling the grain mass more quickly and reducing temperature and moisture content oscillations during the aeration process. Another advantage of AERO is its capacity of automatically adjust its set-points according to the weather conditions of the region where the aeration system is operating.

Keywords: Stored grain, control strategy, aeration, simulation

\footnotetext{
Recebido para publicação em dezembro de 2007 e aprovado em novembro de 2009

${ }^{1}$ Graduada em Ciência da Computação, Doutora. Universidade Federal de São João del-Rei (UFSJ), Campus Alto Paraopeba, Rodovia MG 443, km 07, Fazenda do Catete, 36420000, Ouro Branco, MG, Brasil. danielalopes@ufsj.edu.br.

${ }^{2}$ Engenheiro Agrícola, Ph. Doctor. Universidade Federal de Viçosa (UFV), Departamento de Engenharia Agrícola. Av. PH Rolfs, s/n, 36570-000- Viçosa, MG, Brasil. jhmartins@ufv.br. ${ }^{3}$ Graduado em Engenharia Eletrônica e de Telecomunicações, Doutor. Universidade Federal de Ouro Preto (UFOP), Departamento de Automação, Controle e Técnicas Fundamentais (DECAT). Campus do Morro do Cruzeiro, 35400-000, Ouro Preto, MG, Brasil. paulo@em.ufop.br,

${ }^{4}$ Engenheiro-Agrônomo, Doutor. Universidade Federal de Viçosa (UFV), Departamento de Engenharia Agrícola. Av. PH Rolfs, s/n, 36570-000- Viçosa, MG, Brasil. alacerda@ufv.br.
} 


\section{INTRODUÇÃO}

O principal objetivo da aeração é manter o ambiente de armazenamento em condições que minimizem a migração de umidade e o nível de deterioração dos grãos, impedindo a proliferação de insetos e fungos. A massa de grãos deve apresentar teores de água desfavoráveis ao desenvolvimento da microflora, além de temperaturas baixas e homogêneas que inibam a ação dos insetos (Kaliyan et al., 2007). Portanto, a eficiência de um sistema de aeração depende de um manejo adequado, que relacione o teor de água e a temperatura dos grãos com a temperatura e a umidade relativa do ar ambiente. O consumo de energia é outro fator importante a ser considerado neste sistema, sendo diretamente influenciado pelo tempo requerido para a aeração e pelo fluxo de ar utilizado durante o processo (Navarro \& Noyes, 2001).

Em um sistema de controle automático, estes parâmetros podem ser medidos utilizando sensores e o acionamento do sistema de ventilação pode ser realizado por meio de equipamentos eletrônicos, aumentando a eficácia do manejo da aeração e reduzindo as possibilidades de erros.

Controladores com base em temporizadores ou termostatos têm resultado em um controle adequado da temperatura do ambiente de armazenamento com simplicidade e com baixos custos operacionais. Por esta razão, esses tipos de controladores ainda são bastante utilizados, principalmente por pequenos produtores e em países em desenvolvimento (Maier \& Montross, 1997). Em regiões tropicais e subtropicais, os controladores baseados em umidostatos também são encontrados com facilidade, já que nessas regiões torna-se necessário um controle mais preciso com relação ao teor de água dos grãos. Apesar dos umidostatos necessitarem de manutenção e configuração mais criteriosas, eles são uma opção eficiente e com custo adequado para situações em que o controle da umidade relativa do ar de aeração seja um fator crítico (Navarro \& Noyes, 2001).

Avanços na tecnologia têm contribuído para a utilização de computadores, microprocessadores e circuitos integrados no gerenciamento de unidades armazenadoras. Estes avanços permitem a melhoria na qualidade do armazenamento e na manipulação dos dados, além da possibilidade de desenvolvimento e implantação de estratégias mais sofisticadas para o controle da aeração.

Rodrigo et al. (1999) estudou a aplicabilidade de uma estratégia de controle PID para aeração de grãos baseada em lógica nebulosa. Os resultados indicaram que controladores desse tipo podem ser desenvolvidos em conjunto com sistemas especialistas, visando à obtenção de diferentes parâmetros do ecossistema dos grãos armazenados com relação ao tempo.
O controlador GEMAS, desenvolvido por Monteiro (2001), utiliza dispositivos digitais endereçáveis para realizar a aquisição de dados do sistema em tempo real. Com base nesses dados, um programa computacional relaciona equações psicrométricas do ar com as condições da massa de grãos, decidindo o melhor momento para ligar ou desligar os ventiladores. No GEMAS, uma placa de entradas e saídas digitais é instalada no computador e conectada a relés, tornando possível o acionamento automático do sistema de aeração.

Outros controladores, como o OPI 2000, o Air Master e o Air Control Draw, são gerenciados por programas computacionais que acionam o sistema de aeração de acordo com dados medidos por uma estação meteorológica e termopares ou termistores instalados na massa de grãos. Nesses controladores, as estratégias se baseiam principalmente na equação de teor de água de equilíbrio dos grãos e em limites de temperatura (Kaliyan et al., 2007; Fockink, 2006; Widitec, 2006).

Existem, ainda, controladores cuja estratégia considera a temperatura de bulbo molhado dos grãos. Um exemplo deste tipo de controlador é o mDthT, que aciona o sistema de aeração de acordo com a relação entre as temperaturas de bulbo molhado do ar de aeração e a menor temperatura correspondente na massa de grãos (Winks, 1998).

O controlador de tempo proporcional é outra estratégia sofisticada. Este controlador, chamado CSIRO, opera o ventilador por um número pré-determinado de horas por dia ou por semana, sempre que a temperatura do ar ambiente for menor que um valor estabelecido como limite em um termostato conectado a um temporizador. Este limite configurado no termostato varia, aumentando ou diminuindo o seu valor de acordo com a variação da temperatura do ar ambiente (Darby, 2004).

Uma das razões pelas quais as estratégias de controle sofisticadas não são mais amplamente utilizadas é o fato dos produtores não se adaptarem com facilidade à complexidade do equipamento requerido para a sua aplicação. Também, algumas dessas estratégias requerem atualizações periódicas nas suas condições de controle devido às flutuações de temperatura e de umidade relativa do ar ambiente ao longo do ano. Assim, os produtores são induzidos a abandonar o uso dos controladores sofisticados depois de algum tempo, devido à sua aparente ineficiência (Navarro \& Noyes, 2001).

O controlador AERO é uma alternativa bastante interessante para o manejo de sistemas de aeração, pois relaciona os dados monitorados em tempo real com a simulação do processo, adaptando-se automaticamente a diferentes condições climáticas (Lopes, 2006). Quando comparado a outros controladores com estratégias sofisticadas, o AERO apresenta menor custo, já que o monitora- 
mento realizado por ele se baseia em dispositivos digitais endereçáveis, o que elimina a necessidade de placas de aquisição de dados ou placas de entradas e saídas digitais, diminui consideravelmente a complexidade física do sistema e facilita a sua manutenção (Lopes et al., 2007).

O objetivo neste trabalho foi comparar, por meio de simulações, os efeitos, no ambiente de armazenamento, das estratégias de controle utilizadas pelo AERO e pelos controladores com base em temporizador, termostato e termostato combinado com umidostatos.

\section{MATERIAL E MÉTODOS}

As simulações realizadas utilizaram o modelo matemático unidimensional proposto por Lopes et al. (2006), que é uma adaptação do modelo formulado por Thorpe (1997) e apresentado mais detalhadamente por Thorpe (2001). Esse modelo relaciona as equações psicrométricas do ar com balanços de massa e de energia, estimando as variações de temperatura, teor de água e deterioração dos grãos durante o processo de aeração. Durante a simulação, a massa de grãos foi dividida em quinze camadas na direção vertical. A variação nos parâmetros estimados foi calculada para intervalos de tempo iguais a uma hora, para cada camada de produto, de forma iterativa.

Os dados de entrada para o modelo de simulação foram os dados históricos de temperatura e umidade relativa do ar ambiente, para Viçosa (MG), nos meses de junho de 2005 a setembro de 2005, além do diâmetro do silo (3,6 $\mathrm{m})$, da espessura da massa de grãos (1,7 m), da vazão específica do ar $\left(0,0012 \mathrm{~m}^{3} \mathrm{~s}^{-1} \mathrm{~m}^{-3}\right)$, do produto armazenado (milho) e do teor de água indicado para o armazenamento seguro (13\% b.u.). As configurações da estratégia de controle considerada, a temperatura inicial da massa de grãos e o teor inicial de água da massa de grãos também foram dados de entrada, mas variaram de acordo com o conjunto de testes considerado.

O modelo matemático utilizado foi previamente validado por Lopes (2006) e os resultados indicaram que os valores estimados ajustaram-se aos dados medidos com elevada exatidão. A partir desses resultados foi possível verificar que o modelo prediz de forma bastante eficiente o comportamento da massa de grãos nos momentos em que o sistema de ventilação se encontra ligado e, também, quando o sistema está desligado. Os momentos mais apropriados ao acionamento do sistema também foram estimados de forma bastante adequada.

Para cada conjunto de testes compararam-se o tempo requerido para aeração, a temperatura final da massa de grãos, seu teor final de água e seu nível final de deterioração.

A primeira estratégia analisada foi a do controlador com base em temporizador que consiste em um equipa- mento eletrônico no qual é possível configurar os horários em que o sistema de ventilação deve ser ligado e desligado. Durante as simulações, vários períodos foram testados, mas os melhores resultados foram obtidos quando o sistema de ventilação se manteve ligado entre 18:00 e 24:00 h. Por isso, essa configuração foi utilizada em todas as comparações com outros controladores. De fato, considerando as condições climáticas utilizadas como dados de entrada para a simulação, no período entre as 18:00 e 24:00 h, a combinação de temperatura e umidade relativa do ar ambiente se mostrou mais adequada à aeração. Durante a madrugada foram observados altos valores de umidade relativa, apesar das baixas temperaturas do ar, enquanto que durante o dia foram observados baixos valores de umidade relativa, mas temperaturas bastante elevadas. A Figura 1 apresenta o algoritmo utilizado para simular a estratégia de controle com base em temporizador.

A proposta do controlador com base em termostato é operar o sistema sempre que a temperatura do ar de aeração for menor ou igual a uma temperatura de referência. Também neste caso, várias configurações foram testadas e aquelas que proporcionaram melhores resultados foram empregadas nas comparações. A escolha da temperatura de referência depende dos limites de temperatura acima dos quais a proliferação de insetos pode tornar-se prejudicial ao ambiente de armazenamento.

Em ambientes com temperaturas menores que $18^{\circ} \mathrm{C}$, o desenvolvimento dos insetos é significantemente reduzido e, caso estas temperaturas não estejam próximas do ponto de congelamento, a qualidade dos grãos é mantida. Para regiões tropicais e subtropicais, temperaturas de até $25{ }^{\circ} \mathrm{C}$ são consideradas aceitáveis para grãos armazenados (Ileleji et al., 2007). Com base nessas considerações e nos resultados observados durante os testes realizados, os valores da temperatura de referência para o termostato variaram de 18 a $22{ }^{\circ} \mathrm{C}$ nas comparações com outros controladores. A Figura 2 apresenta o algoritmo utilizado para avaliar a estratégia de controle com base em termostato.

Geralmente, os controladores com base em termostato combinado com umidostatos são mais eficientes que aqueles baseados apenas em temporizadores ou termostatos, pois previnem a entrada de ar muito seco ou muito úmido no ambiente de armazenamento. Nesta estratégia de controle, o acionamento do sistema de ventilação é indicado sempre que a temperatura do ar de aeração for menor que um valor de referência e a umidade relativa do ar de aeração estiver dentro de uma faixa estipulada. Assim como nos casos em que vários termostatos são empregados ou a diferença de temperatura entre o interior e o exterior do ambiente de armazenamento são utilizados como condições de controle, a configuração dos valores de referência para o controlador com base em termostato e 
umidostatos deve ser realizada de forma criteriosa, evitando conflitos que possam prejudicar a operação do sistema de ventilação. Faixas muito extensas ou curtas de valores de umidade relativa podem causar acionamentos excessivos ou limitar o tempo de aeração. Estes efeitos podem ser causados também por combinações de limites muito baixos ou muito altos de temperatura com faixas adequadas de umidade relativa.

O limite inferior ideal de valores de umidade relativa deve ser aquele a partir do qual o teor de água seguro para armazenamento dos grãos é mantido, impedindo perdas quantitativas e qualitativas de produto. O limite superior ideal de valores de umidade relativa deve ser aquele acima do qual o desenvolvimento de microorganismos torna-se prejudicial ao ambiente de armazenamento, para a temperatura considerada. Os microorganismos característicos do ecossistema dos grãos armazenados são os fungos e bactérias, sempre presentes na massa de grãos, mas inativos quando a umidade relativa de equilíbrio do ambiente de armazenamento é menor que 65\%. Quando o valor desse parâmetro ultrapassa 75\% a deterioração causada pelos fungos aumenta a uma taxa exponencial, podendo danificar o produto visualmente e nutricionalmente (Jayas \& White, 2003).

De acordo com essas observações e com os melhores resultados observados durante as simulações, os limites de umidade relativa, configurados quando o controlador, com base em termostatos e umidostatos, foi comparado

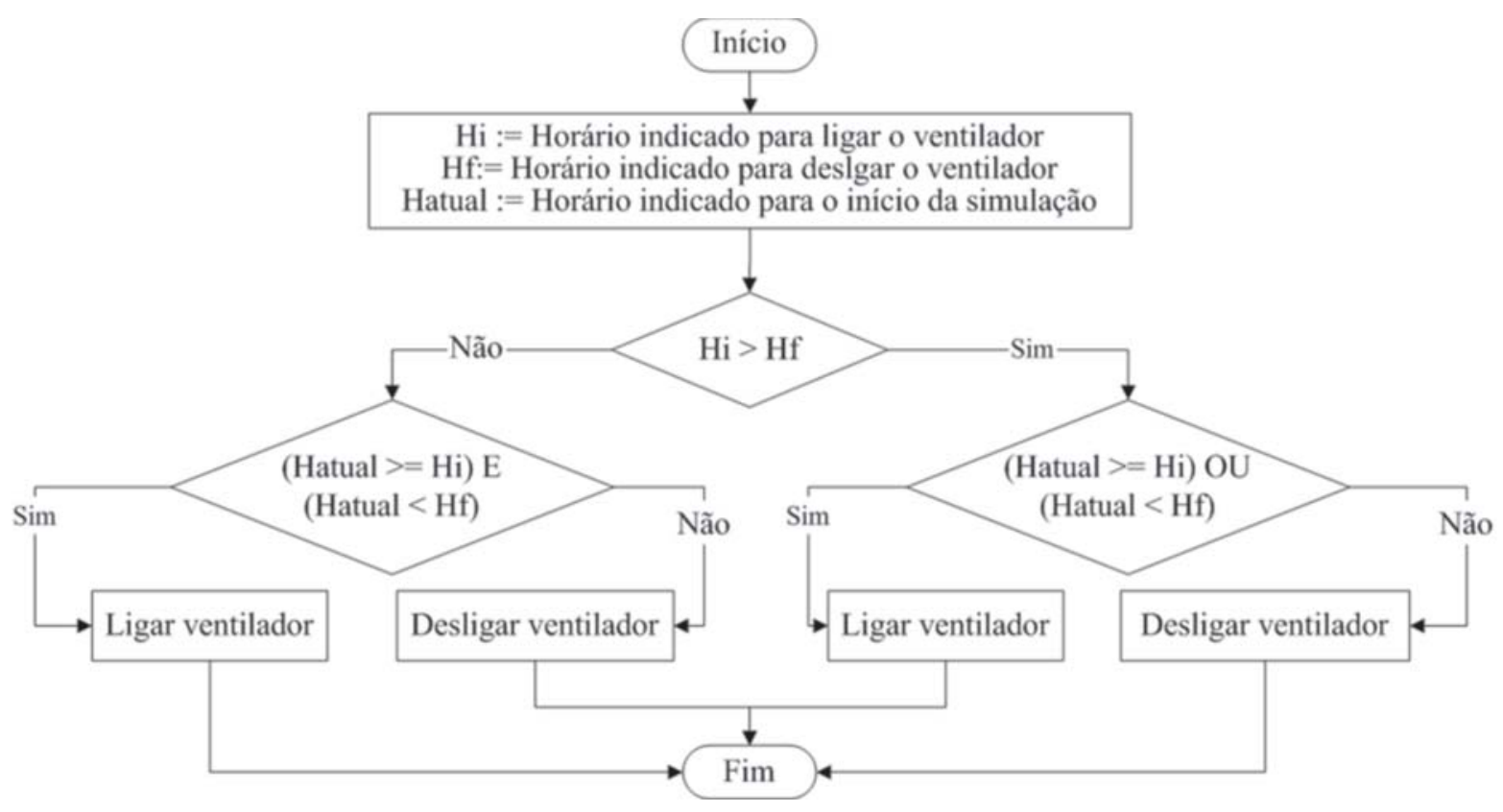

Figura 1. Algoritmo utilizado pela estratégia de controle com base em temporizador.

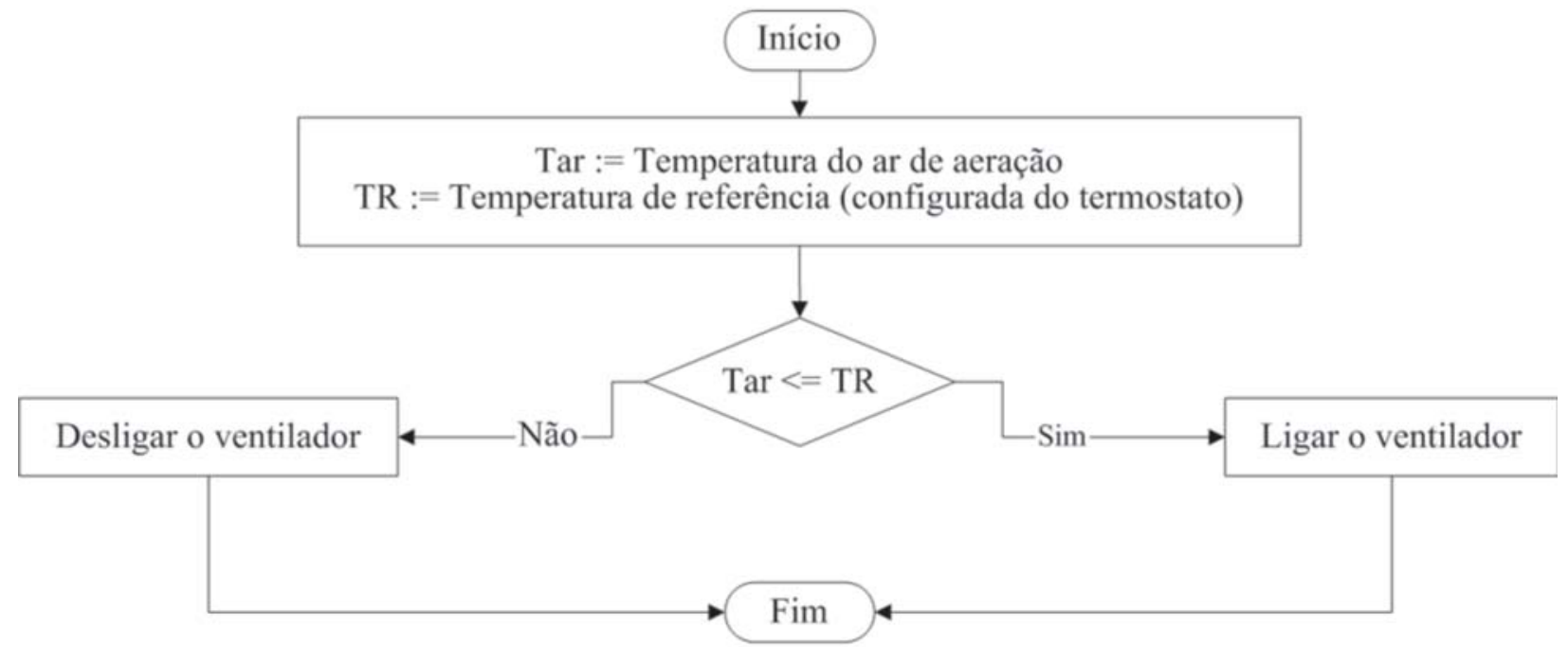

Figura 2. Algoritmo utilizado pela estratégia de controle com base em termostato.

Rev. Ceres, Viçosa, v. 57, n.2, p. 157-167, mar/abr, 2010 
com os outros controladores, foram iguais a 60 e $75 \%$. A temperatura de referência para esse controlador também variou de $18{ }^{\circ} \mathrm{C}$ a $22^{\circ} \mathrm{C}$. A Figura 3 apresenta o algoritmo empregado na análise da estratégia de controle baseada em termostatos e umidostatos.

O controlador AERO utiliza quatro condições para avaliar a necessidade de acionamento do sistema de aeração. A primeira condição (C1), indica ligar o sistema de ventilação quando a temperatura de ponto de orvalho do ar de aeração for menor que a temperatura mínima na massa de grãos. Assim, garante-se que nenhuma área do ambiente de armazenamento receberá ar em condições favoráveis ao acúmulo de umidade (Lacerda Filho \& Afonso, 1992).

De acordo com a segunda condição (C2), o sistema de ventilação pode ser ligado quando a diferença entre o valor estimado do teor de água dos grãos na primeira camada (próxima à entrada de ar) e o teor de água de equilíbrio for menor ou igual a 0,5 ponto percentual. Este valor foi utilizado por ser uma variação considerada aceitável na literatura e porque os fluxos de ar característicos do processo de aeração são baixos, sendo que o teor de água dos grãos tende a não sofrer variações significativas ao longo do período de aeração (Maier \& Montross, 1997). Ainda, se a massa de grãos contiver um teor médio de água maior ou menor que o valor de equilíbrio, o AERO tentará alcançar o valor seguro, permitindo que o sistema de ventilação seja ligado com ar mais úmido ou seco, dependendo da situação. O objetivo dessa condição é acionar o sistema, minimizando variações bruscas no teor de água dos grãos e manter este parâmetro o mais próximo possível do valor de equilíbrio, indicado para o armazenamento seguro.
A terceira condição avaliada pelo AERO (C3) permite ligar o sistema de ventilação quando o gradiente de temperatura dentro do ambiente de armazenamento for maior que $5{ }^{\circ} \mathrm{C}$ e o gradiente de temperatura simulado, considerando o acionamento do sistema, for menor que o atual. Essa condição garante temperaturas homogêneas na massa de grãos, sendo muito importante nas regiões tropicais e subtropicais, onde o resfriamento do produto armazenado até temperaturas inferiores a $18^{\circ} \mathrm{C}$, geralmente, não é alcançado. Assim, nessas regiões, o principal objetivo da aeração deve ser manter gradientes de temperatura inferiores a $3{ }^{\circ} \mathrm{C}$ na massa de grãos, minimizando a migração de umidade. Na prática, especialistas garantem que diferenças de temperatura de até $5{ }^{\circ} \mathrm{C}$ são aceitáveis (Navarro \& Noyes, 2001).

A última condição avaliada pelo AERO (C4) indica ligar o sistema de ventilação quando alguma das temperaturas máximas simuladas para cada camada de grãos, considerando o acionamento do sistema, for menor que o valor atual equivalente a ela ou quando a temperatura média simulada for menor que a atual. Esta condição garante o resfriamento da massa de grãos sempre que possível.

A Figura 4 apresenta o algoritmo simplificado utilizado pelo controlador AERO.

Neste trabalho, três conjuntos de testes foram analisados para cada estratégia de controle. Em todos eles, dados reais de temperatura e umidade relativa foram utilizados para simular a variação das condições do ar ambiente a cada três horas. Essas séries de dados foram obtidas durante um estudo realizado no Departamento de Engenharia Agrícola da Universidade Federal de Viçosa,

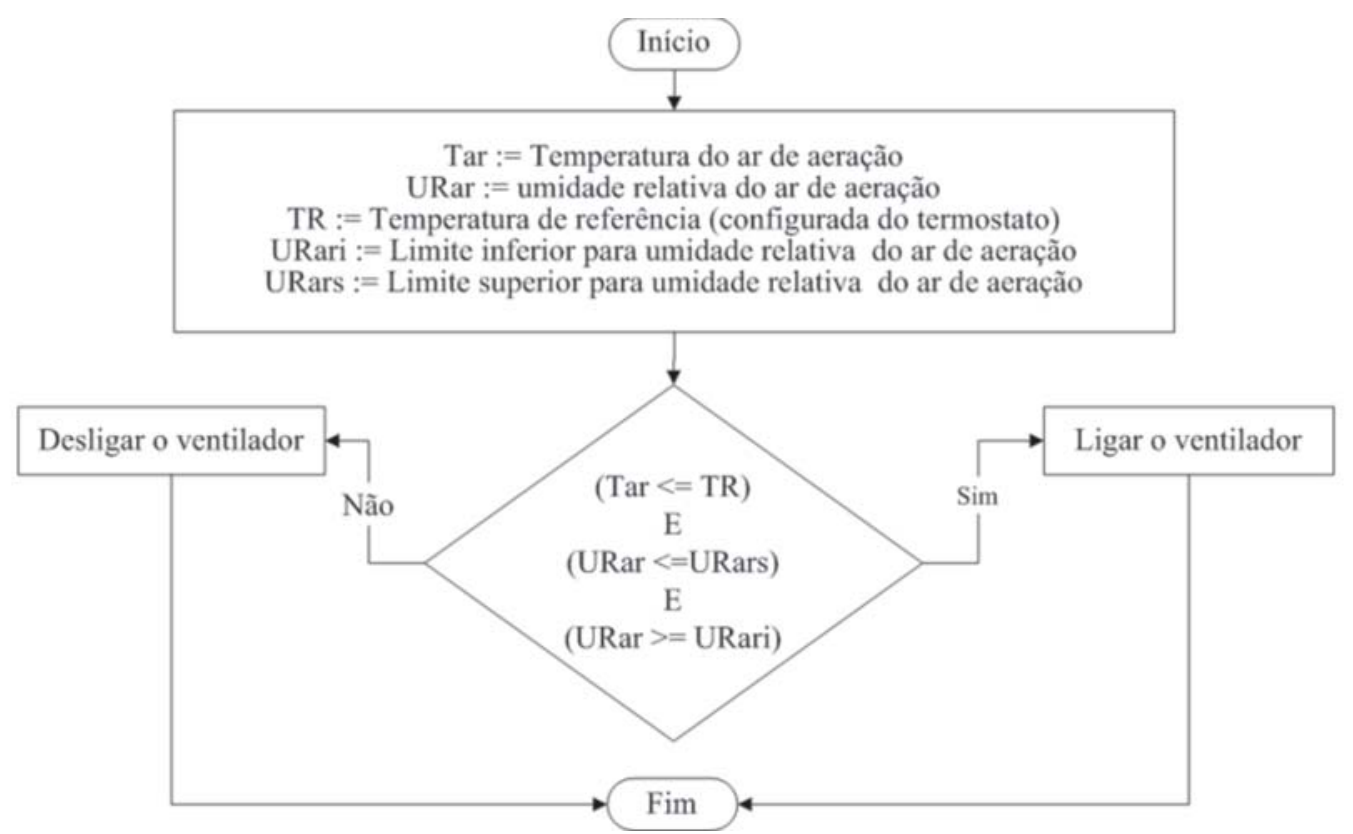

Figura 3. Algoritmo utilizado pela estratégia de controle com base em temporizador combinado com umidostados. 
no período entre junho e setembro de 2005. O tempo de simulação para cada conjunto de testes foi igual a 720 horas, correspondendo a um mês de armazenamento.

No primeiro teste, considerou-se uma situação em que os grãos foram armazenados com temperaturas relativamente altas $\left(26^{\circ} \mathrm{C}\right)$ e teores de água acima do valor indica- do para o armazenamento seguro (14\% b.u.). As temperaturas do ar ambiente variaram de 14,7 a $27,8^{\circ} \mathrm{C}$ e os valores de umidade relativa variaram de 50,1 a 94,7 \%. Esses dados corresponderam aos valores medidos do mês de junho, em Viçosa (MG), simulando condições de inverno em uma região tropical ou subtropical. Apesar das baixas

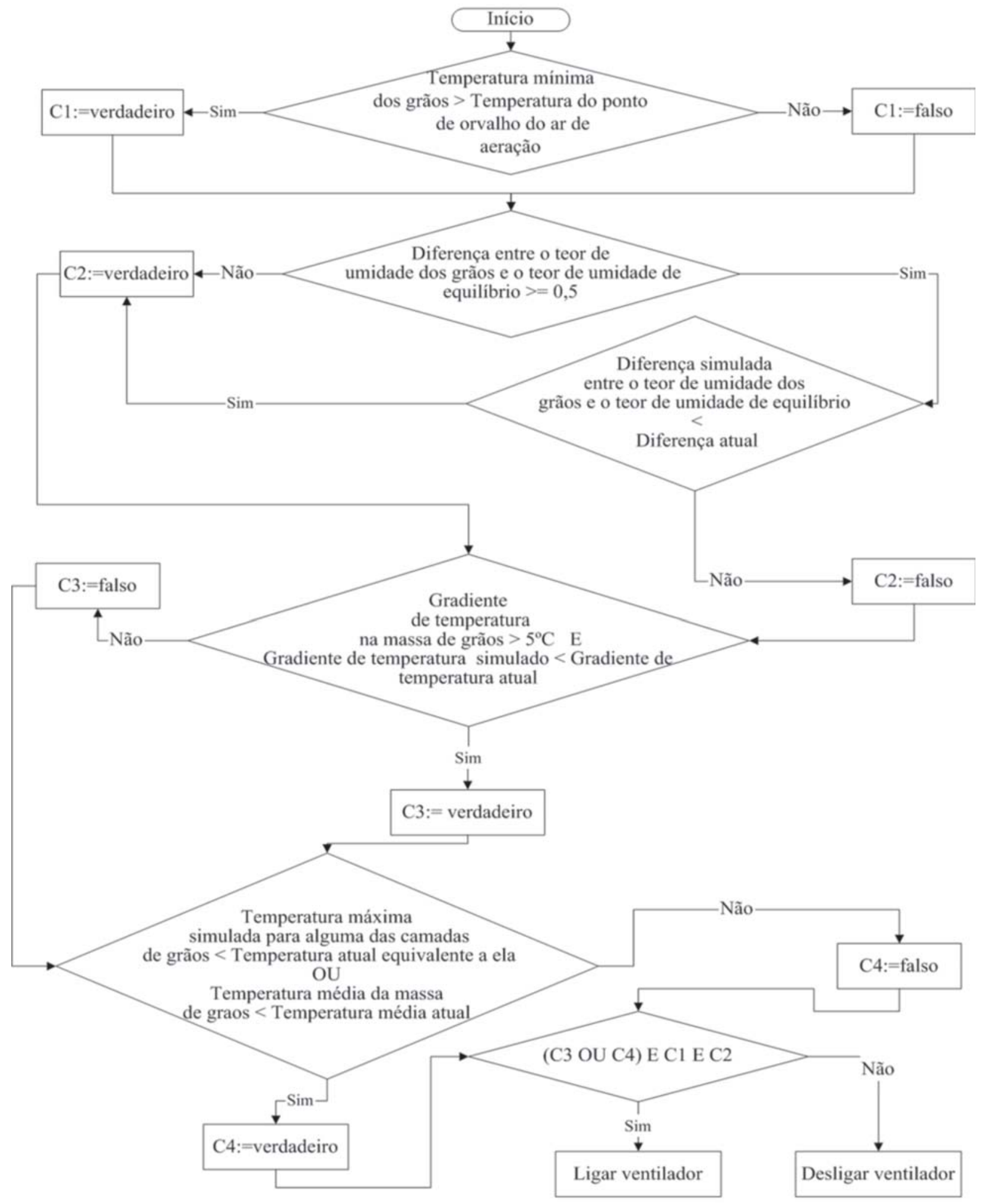

Figura 4. Algoritmo simplificado utilizado pelo controlador AERO

Rev. Ceres, Viçosa, v. 57, n.2, p. 157-167, mar/abr, 2010 
temperaturas observadas para o ar ambiente durante esse teste, o melhor limite de temperatura para o controlador com base em termostatos e umidostatos, foi $20^{\circ} \mathrm{C}$, já que as temperaturas abaixo do valor configurado sempre foram acompanhadas de valores de umidade relativa acima do limite máximo estipulado para o umidostato (75\%). Como o controlador baseado apenas no termostato não dependia de valores de umidade relativa, foi possível configurar a sua temperatura de referência como $18^{\circ} \mathrm{C}$. Como mencionado anteriormente, o temporizador sempre foi configurado para operar entre 18:00 e 24:00 h e os umidostatos sempre para operar entre 60 e $75 \%$. O AERO não precisa ser configurado, pois se ajusta automaticamente às variações climáticas.

No segundo teste, considerou-se uma situação em que os grãos foram armazenados com temperaturas altas $\left(28^{\circ} \mathrm{C}\right)$ e teores de água ligeiramente superiores ao valor indicado para o armazenamento seguro (13,5 \% b.u.). Mas, neste caso, considerou-se o armazenamento em uma região tropical ou subtropical durante a primavera ou outono, em que são observadas temperaturas amenas e grandes variações na umidade relativa. As temperaturas do ar ambiente variaram de 16,6 a $31,8^{\circ} \mathrm{C}$ e a umidade relativa variou de 39,3 a 91,0\%. Essas condições corresponderam ao mês de setembro em Viçosa (MG). Nesse teste, possivelmente devido às poucas ocorrências de temperaturas baixas acompanhadas de umidades relativas adequadas, a melhor configuração para a temperatura de referência foi de $22{ }^{\circ} \mathrm{C}$, tanto para o termostato quanto para o termostato combinado com os umidostatos.

No terceiro teste, considerou-se uma situação em que a massa de grãos se encontrava em condições adequadas ao armazenamento seguro e que deveriam ser mantidas em uma região tropical ou subtropical com temperaturas em elevação. Nestes testes, a temperatura e o teor inicial de água da massa de grãos foram $22^{\circ} \mathrm{C}$ e 13 \% b.u., enquanto os dados do ar ambiente corresponderam ao mês de setembro em Viçosa (MG). Nesse caso, também devido às condições climáticas locais, a melhor temperatura de referência, tanto para o controlador com base em termostato quanto para o termostato combinado com umidostatos, foi igual a $20^{\circ} \mathrm{C}$.

No último teste, os efeitos das estratégias de controle em massas de grãos com focos de calor ou elevados gradientes de temperatura foram avaliados considerando-se uma região tropical ou subtropical durante a transição do inverno para a primavera. Assim, as temperaturas iniciais da massa de grãos variaram de 19 a $25^{\circ} \mathrm{C}$, com teor de água igual igual a $13 \%$ b.u.. Os dados do ar ambiente corresponderam a agosto de 2005 em Viçosa (MG), com temperaturas variando de 12,6 a $30,6^{\circ} \mathrm{C}$ e umidades relativas entre 33,8 e 96,3\%. Nesse teste, verificaram-se mais ocorrências de baixas temperaturas acompanhadas de umidades relativas adequadas à aeração. Portanto, foi possível configurar as temperaturas de referência das estratégias que dependem de termostatos para $18^{\circ} \mathrm{C}$.

\section{RESULTADOS E DISCUSSÃO}

De acordo com os resultados das simulações, pequenas diferenças foram observadas entre as temperaturas, perdas de matéria seca e teores de água finais alcançados pelas estratégias analisadas, assim como entre os tempos requeridos para aeração. Mas, em todos os testes verificou-se que o controlador AERO apresentou-se mais eficiente no controle, minimizando as oscilações de temperatura e teor de água dos grãos durante o processo, resfriando a massa de grãos mais rapidamente e, na maioria dos casos, requerendo menor tempo de aeração.

A Figura 5 apresenta os níveis finais de deterioração (Figura 5A), a variação no teor de água dos grãos (Figura $5 B$ ), a variação na temperatura dos grãos (Figura 5D) e os tempos requeridos para aeração (Figura 5C) para cada controlador durante o primeiro teste.

Observando a Figura 5, é possível verificar que o temporizador operou durante mais tempo que o AERO e o termostato, alcançando maior nível de deterioração e menor nível de resfriamento quando comparado aos demais controladores.

Com relação ao teor de água dos grãos, o temporizador acompanhou os bons resultados dos outros controladores. Neste teste, o controle com base no termostato foi mais eficiente que o temporizador e o controlador com base em umidostatos, tanto com relação ao tempo requerido para a aeração quanto ao controle do teor de água dos grãos. O aumento indesejável no teor de água, observado durante o controle com umidostatos, e o elevado tempo de aeração requerido por este controlador, são exemplos dos efeitos da migração de umidade devido ao armazenamento de grãos com teor de água acima do valor de equilíbrio. Ou seja, depois de um resfriamento relativamente rápido no início do processo, o sistema de ventilação foi acionado em momentos em que o ar ambiente apresentava temperatura ligeiramente inferior à da massa de grãos, mas umidade relativa acima do valor de equilíbrio para o produto armazenado, o que resultou em adsorção de água pelos grãos. Como as condições do ar de aeração e da massa de grãos estavam muito próximas, tendendo ao equilíbrio, a velocidade da frente de resfriamento foi menor e o sistema operou mais tempo para alcançar o mesmo resultado dos outros controladores. Ainda considerando o controlador com base em umidostatos, a configuração de faixas mais amplas para a umidade relativa resultaria em um controle praticamente igual ao do termostato. Ainda assim, devido ao seu menor custo operacional, o termostato seria o controlador com melhor desempenho nesta situação. 

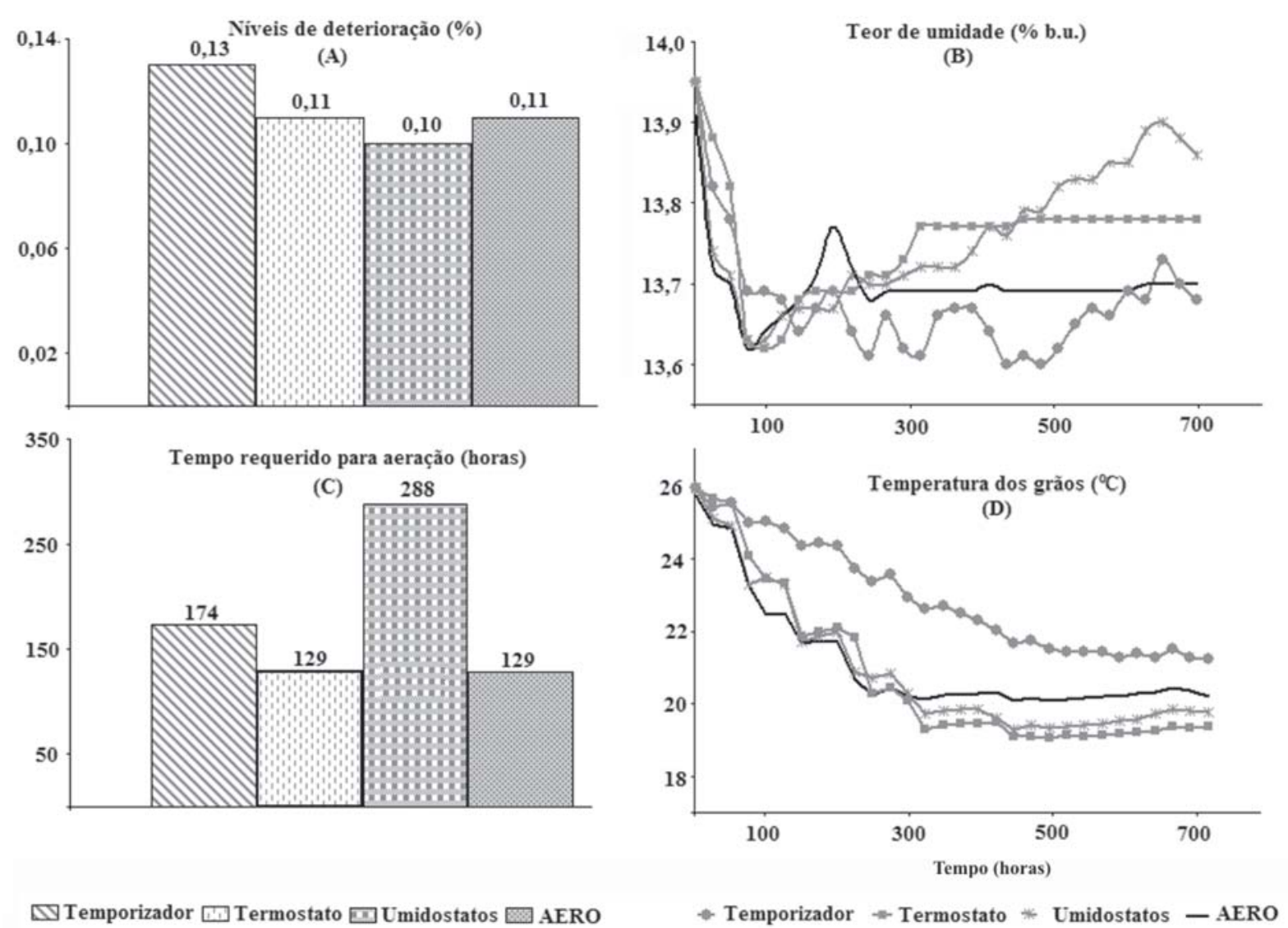

$\square$ Temporizador $\square$ Termostato $\square$ Umidostatos $\square$ AERO

Figura 5. Efeitos das diferentes estratégias de controle considerando grãos armazenados a $26{ }^{\circ} \mathrm{C}$ e $14 \%$ b.u. em uma região com temperaturas variando de $14,67^{\circ} \mathrm{C}$ a $27,75^{\circ} \mathrm{C}$ e umidades relativas entre $50,06 \%$ e $94,65 \%$.

Os resultados observados com o controlador AERO se aproximaram dos obtidos com o termostato, principalmente em relação à temperatura da massa de grãos, ao nível de deterioração e ao tempo requerido para a aeração. Com relação ao controle do teor de água, o AERO se mostrou mais eficiente que o termostato, resultando em menores oscilações deste parâmetro durante o processo, além de alcançar valores de umidade próximos ao indicado para o armazenamento seguro. Os resultados comprovam que controladores mais sofisticados, como o AERO, possibilitam um controle mais eficiente. Apesar de ser uma estratégia mais elaborada, envolvendo a simulação do processo e o relacionamento de diferentes variáveis do ecossistema dos grãos armazenados, esta estratégia proporciona uma estimativa confiável do comportamento deste ecossistema, evitando conflitos entre as condições analisadas e sendo mais flexível do que as estratégias baseadas em configurações pré-determinadas.

A Figura 6 apresenta os efeitos da aeração para cada controlador durante o segundo teste. Para este teste, verificou-se que, apesar de terem sido observados o tempo de aeração (Figura 6B) e o controle do teor de água (Figura 6C) semelhantes aos outros controladores, o temporizador novamente resultou em maior nível de deteriora- ção (Figura 6A) e menor eficiência no controle de temperatura (Figura 6D). Nesta situação, mesmo apresentando tempo de aeração maior que os demais controladores, o AERO se destacou, resfriando o produto mais rapidamente, atingindo valores de teor de água mais próximos do equilíbrio e minimizando as oscilações destes parâmetros durante o processo de aeração.

A Figura 7 apresenta os resultados obtidos com o terceiro teste. Nesse caso, ressalta-se a diferença de resultados entre o temporizador e os outros controladores. As condições adequadas ao armazenamento incluem teor de água próximo ao equilíbrio, diferença de temperaturas dentro do silo menores que $3^{\circ} \mathrm{C}$ e baixa temperatura da massa de grãos. Em regiões tropicais e subtropicais, verificam-se temperaturas médias do ar ambiente próximas dos $25{ }^{\circ} \mathrm{C}$ ou superiores, condições estas bem parecidas com as observadas no terceiro teste. Neste caso, o baixo valor do gradiente de temperatura na massa de grãos, assim como entre o produto armazenado e o exterior do silo, se torna condição primordial para a manutenção da qualidade do produto armazenado. As variações das condições do ar externo ao silo durante os períodos diurno e noturno resultaram em pequenas alterações na temperatura, umidade e entalpia do ar de aeração. Ainda assim, as con- 

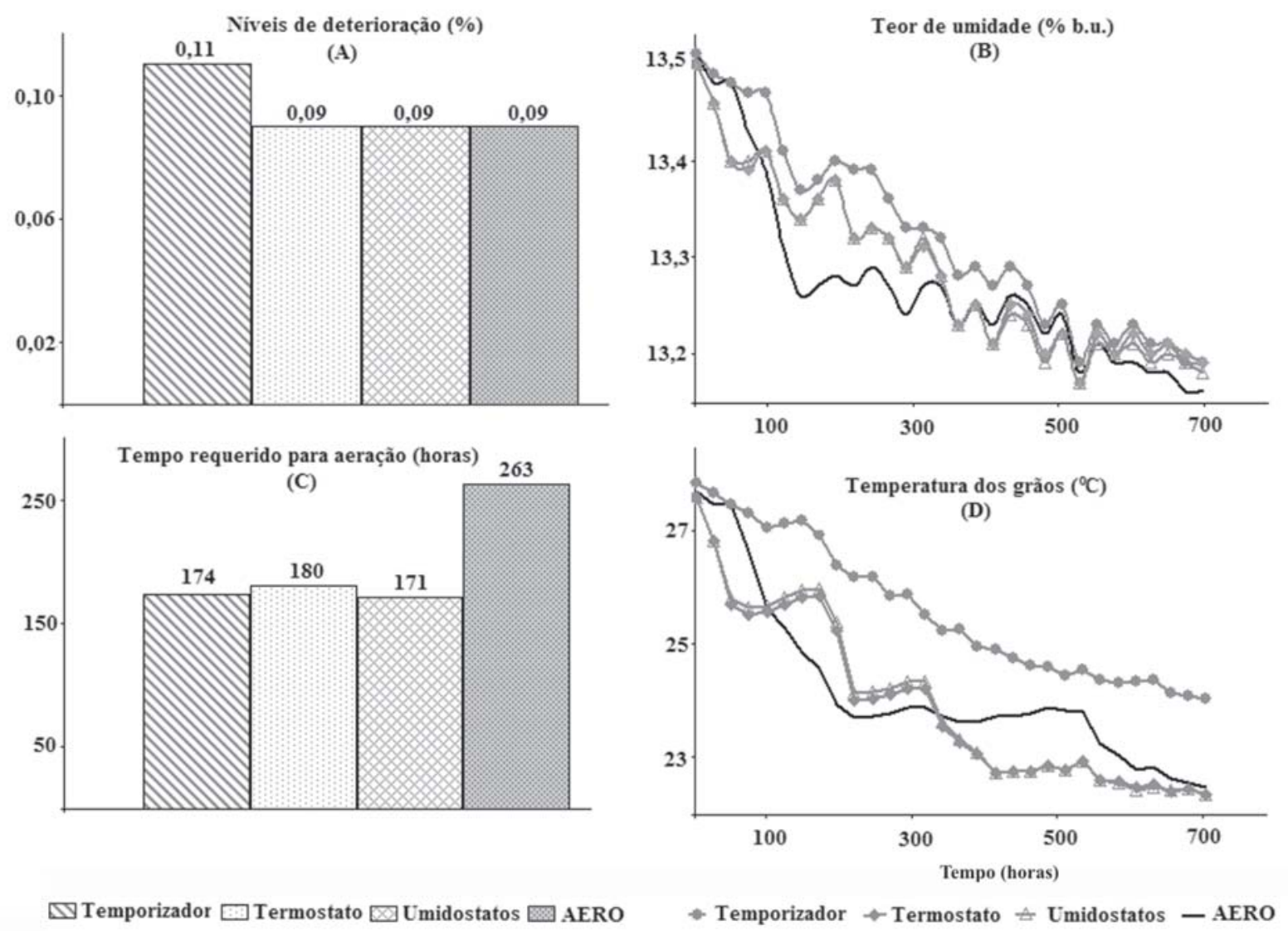

Figura 6. Efeitos das diferentes estratégias de controle considerando grãos armazenados a $28{ }^{\circ} \mathrm{C}$ e $13,5 \%$ b.u. em uma região com temperaturas variando de $16,59^{\circ} \mathrm{C}$ a $31,75^{\circ} \mathrm{C}$ e umidades relativas entre $39,27 \%$ e $91,04 \%$.

dições do ar de aeração se mantiveram próximas às condições observadas na massa de grãos. No caso do temporizador, o resultado foi a operação do sistema em momentos desnecessários, devido ao fato do seu acionamento depender apenas de horários pré-estabelecidos. Apesar da pequena diferença no nível de deterioração dos grãos (Figura 7A), essa estratégia de controle apresentou tempo de aeração, aquecimento e umedecimento da massa de grãos bem superiores aos obtidos com os outros controladores (Figuras 7C, 7D e 7B). As outras estratégias apresentaram bons resultados, já que na situação simulada neste teste, o produto estava em condições adequadas ao armazenamento seguro e as condições do ar ambiente não permitiam maior nível de resfriamento. Isso explica o menor tempo requerido para a aeração e o pouco aquecimento dos grãos, observado ao longo do período simulado.

A Figura 8 contém os resultados de tempo de aeração, temperatura, teor de água e deterioração, observadas no último teste. Novamente, o temporizador resultou no controle menos efetivo do nível de deterioração (Figura 8A), teor de água (Figura 8C) e temperatura dos grãos (Figura 8D), necessitando, também, de maior tempo de aeração (Figura 8B). Com relação aos outros controladores, verifi- cou-se maior oscilação dos valores de teor de água do produto armazenado, possivelmente por causa do gradiente de temperatura inicial da massa de grãos que favoreceu a migração de umidade. Mas, estas oscilações não foram significativas e o produto se manteve com teor de água sempre muito próximo ao valor indicado como adequado ao armazenamento seguro. O AERO requereu apenas três horas a mais de aeração que o controlador com base em umidostatos que, nesse caso, foi a estratégia com menor tempo de aeração. Também, a temperatura final dos grãos, obtida com o controlador AERO, foi ligeiramente superior às obtidas com as estratégias baseadas em termostatos e em umidostatos, mas o nível de resfriamento obtido por este controlador se mostrou perfeitamente adequado ao armazenamento seguro, além de ter sido novamente alcançado mais rapidamente e sem gerar grandes oscilações durante o processo de aeração.

As ocorrências de baixas temperaturas em regiões tropicais e subtropicais são raras, geralmente sendo verificadas durante a madrugada e acompanhadas de altos valores de umidade relativa. Assim, estratégias de controle que dependam de temperaturas de referência são difíceis de configurar nessas regiões. Valores muito baixos para esse parâmetro podem limitar o tempo de aeração 

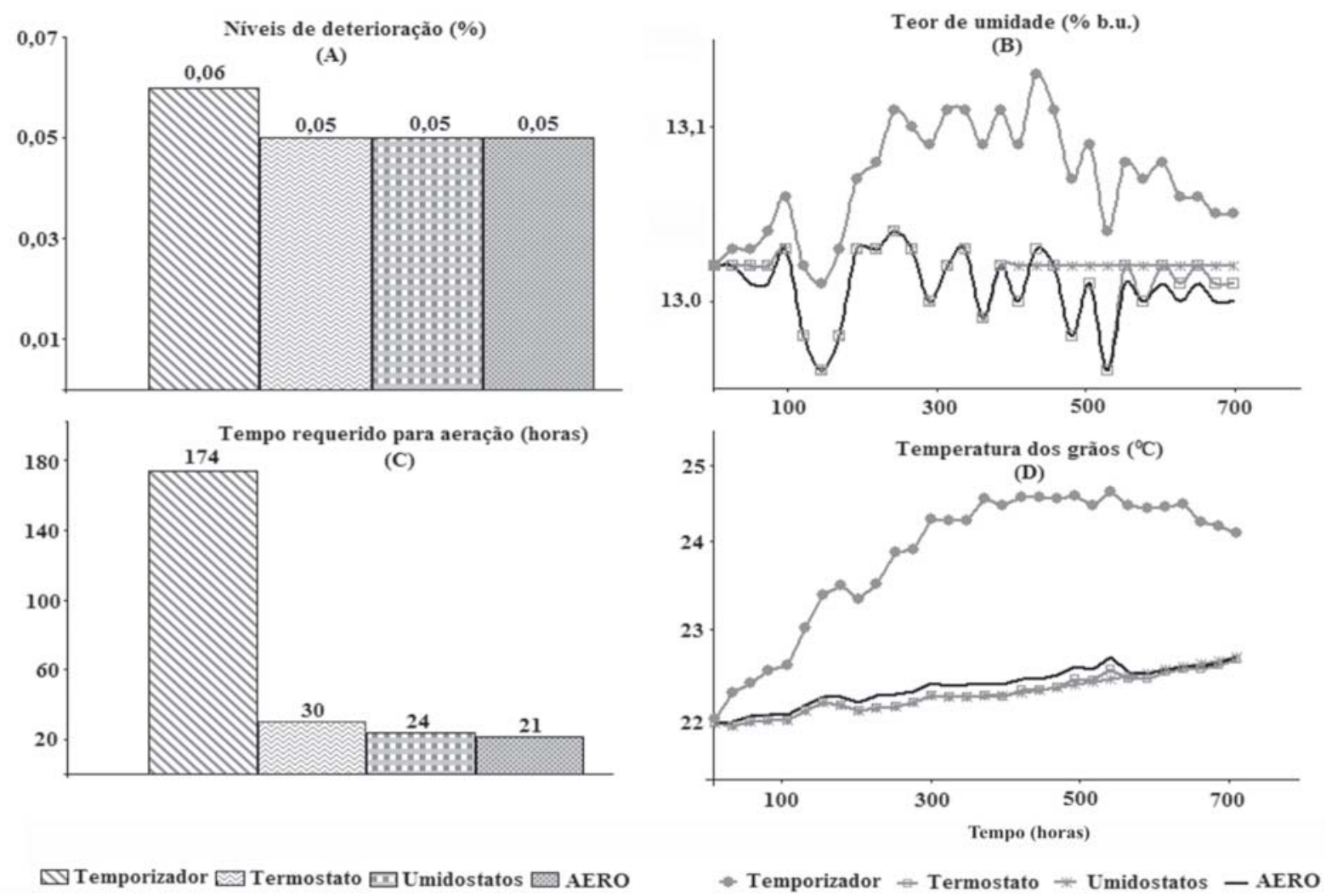

Figura 7. Efeitos das diferentes estratégias de controle considerando grãos armazenados a $22{ }^{\circ} \mathrm{C}$ e $13 \%$ b.u. em uma região com temperaturas variando de $16,59{ }^{\circ} \mathrm{C}$ a $31,75^{\circ} \mathrm{C}$ e umidades relativas entre $39,27 \%$ e $91,04 \%$.
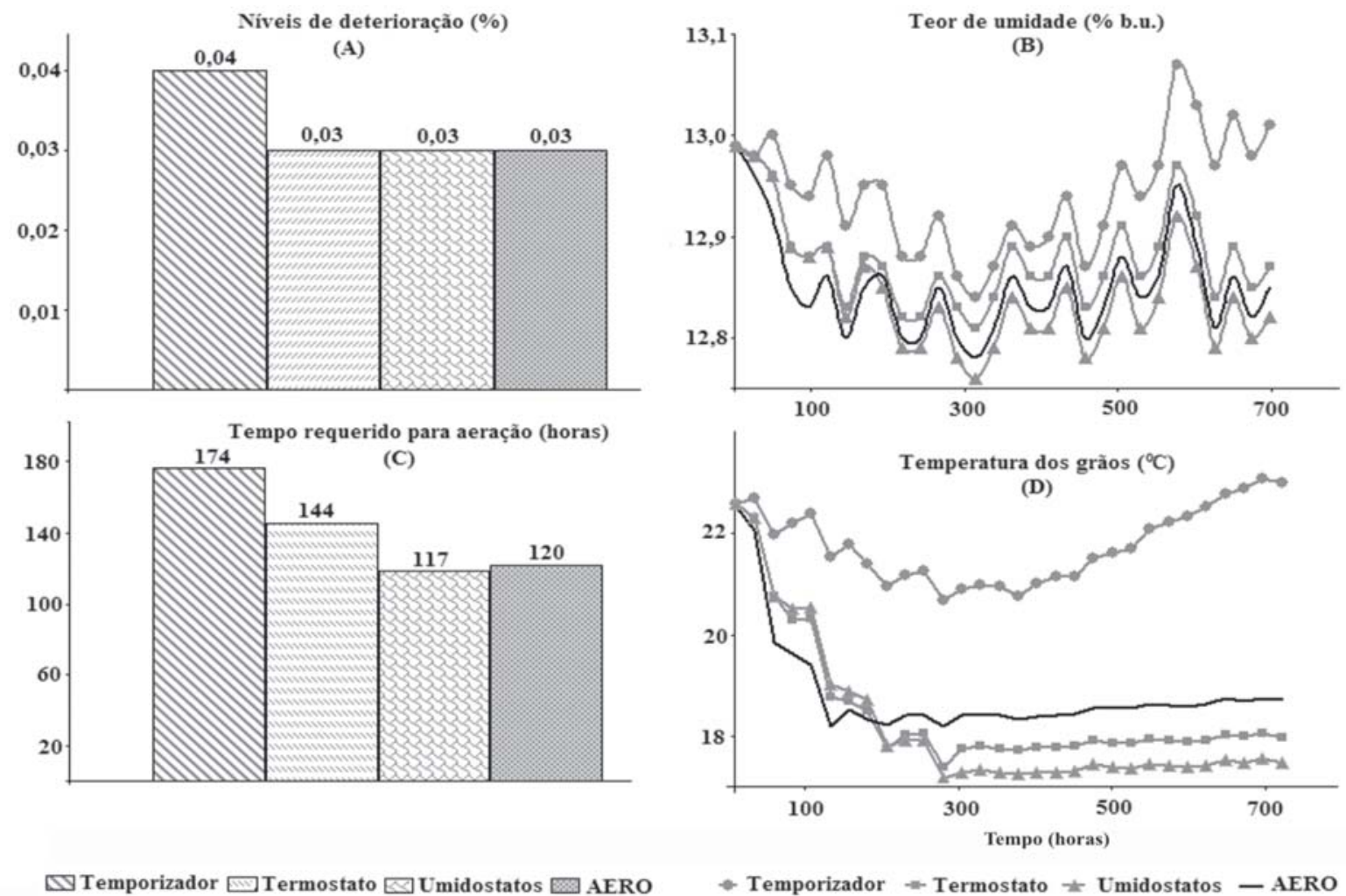

$\square$ Temporizador $\square$ Termostato $\square$ Umidostatos $\square$ AERO

- Temporizador - Termostato $\neq$ Umidostatos - AERO

Figura 8. Efeitos das diferentes estratégias de controle considerando grãos armazenados com temperaturas variando de $19^{\circ} \mathrm{C}$ a $26^{\circ} \mathrm{C}$ e $13 \%$ b.u. em uma região com temperaturas entre $12,63{ }^{\circ} \mathrm{C}$ e $30,64{ }^{\circ} \mathrm{C}$ e umidades relativas entre $33,83 \%$ e $96,29 \%$. 
e o controle das condições do produto armazenado, enquanto valores muito altos podem permitir a entrada de ar excessivamente úmido no ambiente de armazenamento. Assim, torna-se claro que, mesmo para controladores simples, a configuração de condições de controle em regiões tropicais e subtropicais requer amplo conhecimento das condições climáticas da região onde o sistema está implantado e das variáveis que afetam o ecossistema dos grãos armazenados.

Apesar de o controlador AERO requerer sensores exatos e calibrados, além de um computador para monitorar e controlar o acionamento sistema de ventilação, ele é capaz de ajustar as suas condições de controle automaticamente, de acordo com diferentes regiões, estações do ano e sistemas de aeração. Isso ocorre devido ao fato do AERO simular o processo de aeração considerando o sistema de ventilação ligado e relacionar esses resultados com os dados medidos em tempo real. Assim, utilizando o AERO, o usuário deverá configurar os dados de entrada do sistema apenas quando for executá-lo pela primeira vez, informando quantos sensores serão utilizados, quantos silos serão controlados, as dimensões das estruturas, os produtos armazenados e as vazões de ar empregadas. Essas vantagens contrastam com as características de outros controladores, cujas configurações devem ser periodicamente ajustadas, sendo difícil para o produtor predizer as variações reais nas condições climáticas e estipular valores de referência ótimos para as estratégias.

\section{CONCLUSÃO}

Os resultados obtidos com as simulações realizadas indicaram que o AERO e os controladores baseados em termostatos e em umidostatos são eficientes no controle do ambiente de armazenamento de grãos. Entretanto, o controlador AERO apresenta vantagens significativas com relação aos outros controladores, como o ajuste automático das condições de controle para diferentes situações, proporcionando o resfriamento mais rápido e as menores oscilações de temperatura e teor de água dos grãos durante o processo de aeração.

\section{REFERÊNCIAS}

Darby J (2004) Aeration increases marketing choices. Farming Ahead, 144:26-28.

Fockink (2006) Sistemas de termometria. Grupo Fockink. Panambi, Brasil. Disponível em: http://portal.fockink.ind.br. Acessado em: 15 de maio 2007.

Ileleji KE, Maier DE \& Woloshukb CP (2007) Evaluation of different temperature management strategies for suppression of Sitophilus zeamais (Motschulsky) in stored maize. Journal of Stored Products Research, 43:480-488.

Jayas DS \& White NDG (2003) Storage and drying of grain in Canada: low cost approaches. Food Control, 14:255 - 261.
Kaliyan N, Morey RV, Wilcke WF \& Carrilo MA (2007) A. Lowtemperature aeration to control Indianmeal moth, Plodia interpunctella (Hübner), in stored grain in twelve locations in the United States: a simulation study. Journal of Stored Products Research, 43:177-192.

Lacerda Filho AF \& Afonso ADL (1992) Algumas considerações sobre aeração de grãos agrícolas. Notas de aula. Universidade Federal de Viçosa. 37p.

Lopes DC (2006) Simulação e controle em tempo real para sistemas de aeração de grãos. Tese de Doutorado. Universidade Federal de Viçosa, Viçosa. 135p.

Lopes DC, Martins JH, Melo EC \& Monteiro PMB (2006) Aeration simulation of stored grain under variable air conditions. Postharvest Biology and Technology, 42:115-120.

Lopes DC, Martins JH, Monteiro PMB \& Queiroz DM (2007) Redes 1-wire ${ }^{\mathrm{TM}}$ aplicadas à aeração de grãos armazenados. Acta Scientiarum, 29:157-163.

Maier D \& Montross M (1997) Aeration technology for moisture management. In: Proceedings of the University of IIIinois Grain Quality Conference. p.100-104.

Monteiro PMB (2001) Tecnologia 1-wire ${ }^{\mathrm{TM}}$ aplicada ao controle em tempo real de sistemas de aeração de grãos. Tese de Doutorado. Universidade Federal de Viçosa, Viçosa. 135p.

Navarro S \& Noyes R (2001) The mechanics and physics of modern grain aeration management. Boca Raton, CRC Press, FL. 647 p.

Rodrigo MA, Seco A, Ferrer J, Penya-roja JM \& Valverde JL (1999) Nonlinear control of an activated sludge aeration process: use of fuzzy techniques for tuning PID controllers. ISA Transactions, 38:231-241.

Thorpe GR (1997) Modelling ecosystems in ventilated conical bottomed farm grain silos. Ecological Modelling, 94:255-286.

Thorpe GR (2001) Physical basis of aeration. In: Navarro, S., Noyes, R.T. (Eds.), The mechanics and physics of modern grain aeration management. Boca Raton, CRC Press. p.125-194.

Widitec (2006) Sistema computadorizado com aeração. Empresa Widitec. Panambi, Brasil. Disponível em http:// www.widitec.com.br. Acessado em: 19 de maio de 2006.

Winks RG (1998) A fan controller to maximize the rate of drying of macadamia nuts-in-shell in farm silos with ambient air. Australian Macadamia Society News Bulletin, 24:47-51. 